\title{
Patients' and Caregivers' Experiences with the Multi-Payer Advanced Primary Care Practice Demonstration
}

\author{
Ellen K. Wilson, $\mathrm{PhD}^{7}$ (D), Noëlle Richa Siegfried, $M F A^{2}$, and Asta V. Sorensen, $M A^{3}$ \\ 'RTI International, Research Triangle Park, NC, USA; ${ }^{2}$ RTI International, Research Triangle Park, NC, USA; ${ }^{3}$ Mathematica, Washington, DC, USA.
}

BACKGROUND: The patient-centered medical home (PCMH) model aims to improve primary health care using a patient-centered approach. Little qualitative research has investigated how the PCMH model affects patient experience with care.

OBJECTIVE: To understand Medicaid and Medicare patient and caregiver experiences with PCMHs participating in the Multi-Payer Advanced Primary Care Practice (MAPCP) Demonstration.

DESIGN: Qualitative study.

PARTICIPANTS: Medicare, Medicaid, and dually eligible patients who were patients in primary care practices participating in the MAPCP Demonstration and caregivers of such patients $(N=490)$.

APPROACH: From July through November 2014, a trained facilitator conducted 81 focus groups in the eight states participating in the MAPCP Demonstration. Separate groups were held for Medicare high-risk, Medicare low-risk, Medicaid, and dually eligible beneficiaries, their caregivers, and caregivers of Medicaid children (or, in Vermont, with patients participating in the Support and Services at Home program), in two different geographical areas in each state. Focus group discussions were recorded, transcribed, and analyzed using NVivo qualitative data analysis software.

RESULTS: Participants' experiences with care were generally consistent with the expectations of a PCMH, although some exceptions were noted. Medicaid only and dually eligible beneficiaries generally had less-positive experiences than Medicare beneficiaries. Most participants said their practices had not solicited feedback from them about their experiences with care. Few participants knew what the term "medical home" meant or were aware that their practices were working to become PCMHs, but many had noticed changes in recent years, primarily related to the conversion to electronic health records.

CONCLUSIONS: Most participants had positive experiences with their care. Opportunities exist, however, to improve care for Medicaid and dually eligible beneficiaries, and enhance patient awareness of and involvement in $\mathrm{PCMH}$ practice transformation.

Prior Presentations This analysis was presented as a podium presentation at AcademyHealth's State Health Research and Policy Interest Group Meeting on June 13, 2015, in Minneapolis, MN, and as a poster at AcademyHealth's Annual Research Meeting, also in Minneapolis, on June 15, 2015.

Received November 27, 2019

Accepted August 24, 2020

Published online September 11, 2020
KEY WORDS: patient-centered medical home; Medicare; Medicaid; focus groups; patient experience.

$\mathrm{J}$ Gen Intern Med 35(1 1):3181-7

DOI: $10.1007 / \mathrm{s} 11606-020-06177-3$

(c) Society of General Internal Medicine 2020

\section{INTRODUCTION}

In recent years, Centers for Medicare \& Medicaid Services (CMS) and other payers have invested significant resources in testing the patient-centered medical home (PCMH) model as a means to improve the organization and delivery of primary health care and reduce health care expenditures. Goals of the PCMH model are to improve patient access to care, improve coordination and quality of care, and increase patient participation in health-related decisionmaking and self-management. ${ }^{1,2}$ Understanding how the PCMH model affects patient experience with care is essential to assessing the model's overall impact and identifying areas in need of improvement. Quantitative studies to date have shown mixed but promising results. ${ }^{3-7}$ Qualitative research allows for more in-depth exploration and deeper understanding of patients' experiences of care, but little work has been done in this area.

The Multi-Payer Advanced Primary Care Practice (MAPCP) Demonstration provides an opportunity to explore the effects of PCMH transformation across a broad variety of populations, health care systems, and geographic areas. The MAPCP Demonstration began in 2011 when the CMS joined ongoing PCMH initiatives in eight states (Maine, Michigan, Minnesota, New York, North Carolina, Pennsylvania, Rhode Island, and Vermont). Through CMS's involvement, Medicare partnered with Medicaid and commercial payers to make payments to participating primary care practices to support PCMH transformation activities, including extending office hours, staffing care teams, coordinating care, and enhancing electronic health record (EHR) capabilities. By the end of 2014, 857 advanced primary care practices were participating in the demonstration.

This paper describes the perspectives of patients and patient caregivers from practices participating in the MAPCP Demonstration regarding their experiences with aspects of their care that are expectations for a PCMH (i.e., enhanced access to care, high-quality and coordinated care, support for shared decision-making and patient self-management, and solicitation of patient input) and how their care had changed since their practices' PCMH transformation. 


\section{METHODS}

\section{Sampling and Recruitment}

The study design was to hold 12 focus groups in each of the eight MAPCP Demonstration states - one group for each of six categories in two separate geographical regions, including both rural and urban areas. The six categories were Medicare high-risk (defined as having a Hierarchical Condition Category score $\geq 1.22$ ), Medicare low-risk, Medicaid, Medicare/ Medicaid dually eligible beneficiaries, caregivers of Medicaid or Medicare beneficiaries, and caregivers of Medicaid children (in Vermont, groups were conducted with participants of the Support and Services at Home [SASH] program, which provided support services and care coordination to Medicare beneficiaries living in subsidized housing and the surrounding communities, instead of caregivers of Medicaid children). We aimed to recruit 10 people per group, with the goal of having 6-8 participants.

We recruited participants by mailing letters to Medicare, Medicaid, and dually eligible beneficiaries inviting them or their caregivers to participate. To identify Medicare and dually eligible beneficiaries, we selected six MAPCP Demonstration practices in each of two regions of each state and then used the Medicare enrollment database to select a random sample of beneficiaries attributed to those practices who met the following criteria: age 18 or older, had been assigned to a MAPCP Demonstration practice for more than 1 year, and had visited the practice at least twice in the prior 12 months. To identify Medicaid beneficiaries and the caregivers of children with Medicaid, four practices in each state generated a random sample of Medicaid beneficiaries who had received care at those practices over the prior 12 months and mailed the recruitment letter to the sample on the study's behalf.

The recruitment letter asked beneficiaries to call to be screened for eligibility. To be eligible to participate, beneficiaries had to be proficient in English and not have participated in a focus group in the prior 12 months; they also had to confirm that they had either Medicare or Medicaid insurance and that they received their primary care from a practice participating in the MAPCP Demonstration. To ensure that beneficiaries and caregivers had sufficient experience with the practice to be able to speak knowledgably about it and that they would be able to address questions about coordination with specialists, they also had to have seen a specialist at least once in the prior year and have a chronic condition.

Because contact information for beneficiaries' caregivers was not available, the recruitment letters to beneficiaries also invited caregivers to call and be screened for eligibility. A caregiver was defined as the main person responsible for the beneficiary's health care who usually or always took the beneficiary to appointments at his or her primary care practice. To capture a broader variety of experiences, we did not recruit both a beneficiary and their caregiver.

If we did not receive a sufficient number of incoming calls to recruit 10 participants for any of the Medicare and dually eligible groups, we called beneficiaries from among those who received recruitment letters to identify additional participants. We were unable to supplement the Medicaid groups in this way because we did not have contact information for the Medicaid beneficiaries and caregivers.

\section{Data Collection and Analysis}

An experienced focus group moderator facilitated the groups between July and November 2014. All participants read and signed an informed consent form. The moderator followed a discussion guide that explored participants' awareness of the PCMH concept and their experiences with care related to key PCMH constructs. For example, related to access to care, participants were asked about the ease or difficulty of getting an appointment when they needed one; how they could schedule appointments and their satisfaction with those methods; wait times; if they had used a patient portal and if so, their experience with it; and whether the practice had taken any steps to help them reduce use of the emergency room. Participants were also asked whether they had experienced any changes in any of these areas in the previous few years. Groups lasted $1.5 \mathrm{~h}$ on average, and participants were given a $\$ 50$ Visa gift card for their participation. Each group was audio-recorded and transcribed.

To guide our analysis of the data, we developed a coding scheme based on a priori theoretical constructs as well as on themes that emerged from a review of the focus group transcripts. A team of six coders used NVivo qualitative data analysis software to code the transcripts. To refine the coding scheme and ensure that all of the coders were interpreting the codes in the same way, all six coders initially coded the same two transcripts and discussed any discrepancies. Once the team had refined the codebook and reached consensus on how to apply it, they divided the remaining transcripts, coded them, and prepared coding reports. For each state, one team member reviewed the coded reports, analyzed the data to identify patterns and themes, and prepared a report summarizing findings for the state. Though some distinctions were found across the eight states, our analysis focuses on the comprehensive findings from all the states, with differences noted by focus group type when applicable. When summarizing the frequency with which specific views were expressed, we use "few" for fewer than $10 \%$ of participants; "some" for 10 to $25 \%$; "many" for 25 to $50 \%$; and "most" for more than $50 \%$.

\section{RESULTS}

We conducted 81 focus groups with 490 individuals, of whom 80 were caregivers and 410 were beneficiaries (Table 1 ). This is 15 fewer groups than intended: The shortfall is primarily due to the fact that most of the participating practices had very few pediatric patients, so we were able to recruit enough participants for just 1 of the planned 14 focus groups with caregivers of Medicaid children (and even that group had only 3 participants). Twelve people participated in the two focus 
Table 1 Number of Focus Groups and Participants by Category

\begin{tabular}{lll}
\hline \hline Focus group category & $\begin{array}{l}\text { Number of } \\
\text { groups }\end{array}$ & $\begin{array}{l}\text { Number of } \\
\text { participants }\end{array}$ \\
\hline $\begin{array}{l}\text { Medicare beneficiaries_-low- } \\
\text { risk }^{1}\end{array}$ & 15 & 117 \\
$\begin{array}{l}\text { Medicare beneficiaries_-high- } \\
\text { risk }\end{array}$ & 16 & 105 \\
$\begin{array}{l}\text { Medicaid beneficiaries } \\
\text { Dually eligible beneficiaries }\end{array}$ & 15 & 87 \\
$\begin{array}{l}\text { Caregivers of Medicaid or } \\
\text { Medicare beneficiaries }\end{array}$ & 16 & 89 \\
$\begin{array}{l}\text { Caregivers of Medicaid children } \\
\text { Special populations }\end{array}$ & 1 & 77 \\
Total & 2 & 3 \\
\hline
\end{tabular}

${ }^{1}$ Low-risk is defined as having a Hierarchical Condition Category score $<1.22$

${ }^{2}$ In Vermont, groups were conducted with Support and Services at Home (SASH) program participants. SASH provided support services and care coordination to Medicare beneficiaries living in subsidized housing and the surrounding communities

groups of participants in the SASH program in Vermont. Most participants described themselves (or, in the case of caregivers, the person they cared for) as being in very good (25\%), good $(35 \%)$, or fair $(27 \%)$ health, with few on either extreme (Table 2). Almost two-thirds (64\%) were 60 years of age or older, and only $9 \%$ were under age 40 . Sixty percent of participants were female, and a large majority $(83 \%)$ were non-Hispanic White. Nearly one-third $(31 \%)$ of participants had a high school education or less, half $(52 \%)$ had some college or a college degree, and $17 \%$ had more than a college degree. Compared with Medicare beneficiaries, Medicaid and dually eligible beneficiaries were, on average, in worse health, younger, more likely to be female, and had lower levels of education; Medicaid beneficiaries also were more likely to be non-Hispanic Black.

Results from the focus group discussions are presented in the sections that follow and are summarized in Table 3.

\section{Access to Care}

Most participants reported convenient access to care during office hours, and some thought that it had improved in recent years: wait times were short and they could typically get a same-day appointment when needed (although usually not with their primary care providers [PCPs]). After-hours access was more problematic, however: most participants said that their practices' hours were limited to weekdays during the day, forcing participants to visit an urgent care facility or the emergency department when they had an urgent health care need after hours.

The biggest recent change in access described by participants was the addition of patient portals. Participants who had used the portal were enthusiastic about its ability to help them make appointments, check test results, and communicate with their PCPs. As one said, "I like that I'm able to see my test results beforehand, especially if there's something that we've been following for a period

Table 2 Characteristics of Focus Group Participants

\begin{tabular}{|c|c|c|c|c|c|c|c|}
\hline $\begin{array}{l}\text { Participant } \\
\text { characteristics }\end{array}$ & $\begin{array}{l}\text { Total \% } \\
(n=490)\end{array}$ & $\begin{array}{l}\text { Medicare low } \\
\text { risk \% } \%(n= \\
117)\end{array}$ & $\begin{array}{l}\text { Medicare high } \\
\text { risk } \%(n=105)\end{array}$ & $\begin{array}{l}\text { Medicaid \% } \\
(n=87)\end{array}$ & $\begin{array}{l}\text { Dually } \\
\text { eligible \% } \\
(n=89)\end{array}$ & $\begin{array}{l}\text { Caregiver \% } \\
(n=80)\end{array}$ & $\begin{array}{l}\text { Special } \\
\text { populations \% } \\
(n=12)\end{array}$ \\
\hline \multicolumn{8}{|l|}{ Overall health } \\
\hline Excellent & 5.7 & 9.4 & 7.6 & 2.3 & 3.4 & 2.5 & 8.3 \\
\hline Very good & 25.8 & 46.2 & 31.4 & 17.2 & 16.9 & 7.6 & 25.0 \\
\hline Good & 35.8 & 35.0 & 34.3 & 35.6 & 42.7 & 31.6 & 33.3 \\
\hline Fair & 27.4 & 9.4 & 22.9 & 36.8 & 25.8 & 50.6 & 33.3 \\
\hline Poor & 5.3 & 0.0 & 3.8 & 8.0 & 10.1 & 7.6 & 0.0 \\
\hline \multicolumn{8}{|l|}{ Age } \\
\hline $18-29$ & 2.4 & 0.0 & 0.0 & 10.3 & 0.0 & 2.5 & 0.0 \\
\hline $30-39$ & 7.1 & 1.7 & 0.0 & 20.7 & 12.4 & 5.1 & 0.0 \\
\hline $40-49$ & 7.3 & 0.9 & 1.9 & 19.5 & 13.5 & 5.1 & 0.0 \\
\hline $50-59$ & 19.2 & 5.1 & 6.7 & 36.8 & 31.5 & 25.3 & 8.3 \\
\hline $60-69$ & 23.9 & 23.1 & 22.9 & 12.6 & 31.5 & 29.1 & 33.3 \\
\hline $70+$ & 40.2 & 69.2 & 68.6 & 0.0 & 11.2 & 32.9 & 66.7 \\
\hline \multicolumn{8}{|l|}{ Sex } \\
\hline Male & 40.4 & 46.2 & 58.1 & 28.7 & 41.6 & 24.1 & 16.7 \\
\hline Female & 59.6 & 53.8 & 41.9 & 71.3 & 58.4 & 75.9 & 83.3 \\
\hline \multicolumn{8}{|l|}{ Race/ethnicity } \\
\hline Non-Hispanic & 83.3 & 88.9 & 88.9 & 90.5 & 80.9 & 81.0 & 100.0 \\
\hline White & & & & & & & \\
\hline \multicolumn{8}{|l|}{$\begin{array}{l}\text { Non-Hispanic } \\
\text { Black }\end{array}$} \\
\hline & & & & & & & \\
\hline Hispanic & 1.8 & 0.0 & 0.0 & 0.0 & 4.5 & 0.0 & 0.0 \\
\hline Other & 1.8 & 10.3 & 9.5 & 8.6 & 4.5 & 15.2 & 0.0 \\
\hline \multicolumn{8}{|l|}{ Education } \\
\hline $\begin{array}{l}\text { High school degree } \\
\text { or less }\end{array}$ & 30.6 & 16.2 & 16.2 & 56.3 & 39.3 & 32.9 & 33.3 \\
\hline Some college to & 52.2 & 57.3 & 57.1 & 39.1 & 51.7 & 51.9 & 58.3 \\
\hline $\begin{array}{l}4 \text { years of college } \\
\text { More than } 4 \text { years } \\
\text { of college }\end{array}$ & 17.1 & 26.5 & 26.7 & 4.6 & 9.0 & 15.2 & 8.3 \\
\hline
\end{tabular}

For the caregiver focus groups, overall health and age were reported by the caregivers for the beneficiaries for whom they care. Sex, racelethnicity, and education are reported for the caregivers 
Table 3 Ways in Which Patients' Experiences Were or Were Not Consistent with PCMH Principles

\begin{tabular}{|c|c|c|}
\hline $\begin{array}{l}\text { PCMH } \\
\text { characteristic }\end{array}$ & $\begin{array}{l}\text { Consistent with } \\
\text { PCMH }\end{array}$ & $\begin{array}{l}\text { Inconsistent with } \\
\text { PCMH }\end{array}$ \\
\hline Access to care & $\begin{array}{l}\text { Short wait times, } \\
\text { ability to get a same- } \\
\text { day or next-day ap- } \\
\text { pointment } \\
\text { Positive experiences } \\
\text { with patient portals } \\
\text { among those who } \\
\text { used them }\end{array}$ & $\begin{array}{l}\text { Limited access to care } \\
\text { for urgent needs after } \\
\text { hours } \\
\text { Non-use of patient } \\
\text { portals (most } \\
\text { participants) }\end{array}$ \\
\hline $\begin{array}{l}\text { Coordination of } \\
\text { care }\end{array}$ & $\begin{array}{l}\text { Improved transfer of } \\
\text { information within } \\
\text { practices and between } \\
\text { practices, hospitals, } \\
\text { and specialists due to } \\
\text { EHRs } \\
\text { More assistance } \\
\text { scheduling } \\
\text { appointments with } \\
\text { specialists than in the } \\
\text { past }\end{array}$ & $\begin{array}{l}\text { Limited transfer of } \\
\text { information via EHR } \\
\text { when providers are par } \\
\text { of different health care } \\
\text { systems } \\
\text { Limited integration of } \\
\text { mental health } \\
\text { information in EHRs } \\
\text { Limited digestion of } \\
\text { information in EHRs } \\
\text { by providers } \\
\text { Provision of hospital } \\
\text { care by hospitalists } \\
\text { rather than PCPs }\end{array}$ \\
\hline $\begin{array}{l}\text { Patient-centered } \\
\text { care }\end{array}$ & $\begin{array}{l}\text { High quality of care } \\
\text { provided by PCP and } \\
\text { office staff } \\
\text { More holistic } \\
\text { approach to care, } \\
\text { more frequent } \\
\text { follow-ups (some } \\
\text { participants) } \\
\text { Ease of filling } \\
\text { prescriptions, quicker } \\
\text { access to test results } \\
\text { as result of EHRs }\end{array}$ & $\begin{array}{l}\text { Reduced quality of } \\
\text { communication with } \\
\text { PCPs as result of EHRs }\end{array}$ \\
\hline $\begin{array}{l}\text { Shared decision- } \\
\text { making and self- } \\
\text { management sup- } \\
\text { port }\end{array}$ & $\begin{array}{l}\text { PCP engagement in } \\
\text { shared decision- } \\
\text { making and self- } \\
\text { management support } \\
\text { Care management } \\
\text { services for a few } \\
\text { participants } \\
\text { (Medicaid and dually } \\
\text { eligible) }\end{array}$ & $\begin{array}{l}\text { Dismissal of patient } \\
\text { concerns and priorities } \\
\text { (some participants, } \\
\text { mostly Medicaid and } \\
\text { dually eligible) } \\
\text { Lack of specific goals } \\
\text { and written plans }\end{array}$ \\
\hline $\begin{array}{l}\text { Solicitation of } \\
\text { patient feedback }\end{array}$ & $\begin{array}{l}\text { Solicitation of patient } \\
\text { feedback through } \\
\text { patient surveys or } \\
\text { other means (some } \\
\text { participants) }\end{array}$ & $\begin{array}{l}\text { No solicitation of } \\
\text { patient feedback (most } \\
\text { participants) }\end{array}$ \\
\hline $\begin{array}{l}\text { Awareness of } \\
\text { medical home }\end{array}$ & $\begin{array}{l}\text { Favorable } \\
\text { perceptions of the } \\
\text { medical home } \\
\text { concept (most } \\
\text { participants) } \\
\text { Perception that } \\
\text { patient's practice is a } \\
\text { medical home }\end{array}$ & $\begin{array}{l}\text { Lack of awareness of } \\
\text { medical home concept } \\
\text { Concerns about } \\
\text { potential unintended } \\
\text { consequences of } \\
\text { medical homes, e.g., } \\
\text { restricted access to } \\
\text { providers or threats to } \\
\text { privacy (some } \\
\text { participants) }\end{array}$ \\
\hline
\end{tabular}

of time" (low-risk Medicare, New York). However, most participants had not used the portal, and many were not even aware of it. Some were interested in trying it, but others were not because the current process worked for them, they were "technology averse," they were worried about privacy issues, or they did not have a computer or Internet service. In the words of one participant, "I like to talk to people when I make appointments, not hit buttons on a computer"(dually eligible, Vermont).

\section{Coordination of Care}

Participants' experiences with coordination of care varied widely. Most said that information was readily shared between their PCPs, specialists, and hospitals - for example, their PCP knew if they had been in the hospital and was able to access test results from their specialists. Many said that their PCP either visited them in the hospital or called to follow up after they were discharged. Some participants, however, said that information did not readily transfer between the PCP and the hospital or specialists, particularly if they were in different systems. Some said their PCP did not know when they had been in the hospital, or that the PCP did not have access to lab results from the hospital and would order the same tests again.

Most participants thought that the transfer of information had improved in recent years, particularly with the introduction of EHRs. However, some participants noted that the transfer of information did not necessarily mean that their PCPs were coordinating their care for them: they were not sure to what extent their PCPs actually digested the information, and some caregivers, in particular, said that they still felt that they were the ones who had to take the lead in coordinating the care for their loved ones: "The information is there, but I always feel like I have to be the advocate for my mom to say, 'Well, she had this and the results came back that way, so does that mean we need to do something?"' (caregiver, New York).

Some participants mentioned that their practices were providing more assistance in scheduling appointments with specialists than they had in the past. Some Medicaid and dually eligible participants reported, however, that the specialists their PCPs referred them to often would not accept their insurance, so they ended up having to find specialists on their own. A few participants mentioned that their PCPs seemed more willing to provide referrals to specialists than in the past; some considered this an improvement, but some wished the PCP would provide more care themselves, rather than sending them to specialists.

A final change in coordination of care noted by some participants was that during hospital stays, care was increasingly provided by hospitalists, and their PCPs, who knew them best, were not involved with their care. They felt that this practice reduced coordination of care.

\section{Patient-Centered Care}

Most participants thought that their PCPs communicated well with them: listened carefully, explained things thoroughly and in terms they understood, and spent as much time as needed to address all their concerns. On the other hand, some participants (most of whom were in Medicaid or dually eligible groups) said that their PCPs rushed them, allowed them to discuss only one or two concerns per appointment, did not address their emotional or mental health needs, or made assumptions about their needs.

Most participants were also pleased with the office staff at their practices, describing them as friendly, helpful, 
professional, courteous, and efficient, and a few thought that the staff had become more efficient and friendlier in recent years. A few participants had complaints, however, including that staff were rude, were inefficient, did not respect confidentiality, did not transmit messages to their PCPs, or made it difficult to reach the PCP. Again, most of the participants who had negative experiences were in Medicaid or dually eligible groups. As one said, "[The staff] act like they are doing you a favor by taking your Medicaid" (Medicaid, Pennsylvania).

The primary changes that participants noted in patientcentered care related to the introduction of EHRs. Participants said that the EHRs helped to ensure that their PCPs remembered their medical information, facilitated filling prescriptions, and shortened the wait time for getting test results. Many participants had started receiving a printout at the end of their appointments summarizing key information, which most appreciated. Some commented that the EHR did not always work well, especially when first implemented, but that it improved over time. One drawback of EHRs mentioned by some participants, however, was that their PCPs were now typing on the computer during their time with them, and they felt that this made for less personal communication "Sometimes I think they spend more time looking at the computer than looking at you" (low-risk Medicare, Pennsylvania).

A few participants mentioned other changes. Some said that their PCPs took more time to discuss health issues, took a more holistic approach, followed up more, and were more responsive. Others said that the practice seemed to be taking a more proactive approach to care, including administering screeners to assess depression or other health risks, calling patients to remind them about appointments or to tell them when they were due for a test or an appointment, and providing support for non-medical issues, such as transportation or food access. Finally, a few participants noticed a new teambased approach to care - for example, that a nurse would ask them questions before they saw their PCPs; some appreciated this because it made more efficient use of their time with the PCP, but others were frustrated that they had to repeat the same information.

\section{Shared Decision-Making}

Most participants viewed their relationships with their PCPs as partnerships and said that their PCP respected their opinions and preferences and involved them in making decisions about their treatment. Some, however (primarily Medicaid and dually eligible beneficiaries), felt that their PCPs disregarded their perspectives by not focusing on the health concerns most important to them, not taking their health concerns seriously, or pushing them to have treatments or tests they did not want: "I just don't think they listen to me sometimes.... Something's wrong, and... I really wish it could be checked out, not just telling me to go home and relax" (Medicaid, New York). Some participants commented that they thought that, in general, patients need to advocate for themselves to make sure that their concerns are addressed. In the words of one participant, "It seems like I have to take the lead in asking [my PCP] questions about my... diabetes. I have to be very assertive... in getting information from her about diet or medication, things of that sort"(low-risk Medicare, Rhode Island).

A few participants noted some changes in shared decisionmaking. Some commented that their PCPs were now starting appointments by asking open-ended questions, such as "What's concerning you?" or "What are your goals?" Others noted a general shift in approach: "I think [they now] want you to be an active part of the team and not just sit back and be told what to do" (low-risk Medicare, Minnesota).

\section{Self-Management Support}

Most participants said that their PCPs talked to them about things they could do to improve their health, but almost none reported having a written care plan and few indicated that they had set specific health-related goals with their PCPs. Moreover, a few participants said their PCPs talked to them about managing their health only if they, the patients, brought it up, and they wished that the PCPs spent more time discussing prevention. On the other hand, some participants said that their PCPs had given up talking to them about behavior change, because they knew that it would be "in one ear and out the other" (Medicaid, Michigan).

Participants reported receiving varying levels of support for managing their health. Only a few, all of whom were either Medicaid or dually eligible participants, had care managers through their PCPs, who helped with needs such as home care, housework, transportation, housing, employment, emotional support, reviewing medications, setting up appointments, and obtaining needed medical equipment. Nearly all participants who received these services found them to be very helpful. Some participants said that their PCPs had referred them to classes on topics such as smoking cessation, diabetes control, or weight loss. While most found the classes helpful, a few said that they were too basic or not relevant for their situation or that they were not able to attend the classes because they could not afford the cost of the class or transportation to get to the class. A few participants said that their PCPs had offered other supports, such as referring them to a dietitian or nutritionist to help support healthy eating or setting them up with a blood pressure cuff and logbooks to monitor their blood pressure. Some commented, though, that the only support their PCPs gave them to aid behavior change was written information such as a pamphlet, which they found inadequate: "Nothing's been said to either [me or my wife] about diet, especially me being diabetic. I was just handed a pamphlet" (dually eligible, North Carolina).

\section{Solicitation of Patient Input and Awareness of Medical Home}

The extent to which participants reported that their practices solicited feedback from them varied. Many said that their 
practice administered patient surveys or had other mechanisms for soliciting patient input; some participants said that this solicitation of feedback was new.

Almost no participants were familiar with the term "medical home." When the concept was explained to them, most agreed that their practices met the definition of a medical home and most thought a medical home would be a positive thing: "If everybody's involved in your situation, it's kind of like a brainstorm type thing, you know? If they're all working together, it could... be a lot more beneficial to everybody" (Medicaid, Rhode Island). Some participants expressed concerns about the medical home concept, however. Some thought that PCPs did not have time to fulfill the role envisioned under a medical home: "If doctors are so busy, how are they going to have time to look at records of everybody who don't necessarily have a problem?" (high-risk Medicare, Rhode Island). Others were concerned that the medical home concept could increase bureaucracy, restrict patients' access to providers, increase costs to patients, or threaten patient privacy. Some felt that they personally did not need a medical home, but it could benefit those with more health problems.

\section{DISCUSSION}

The PCMH paradigm is complex and primary care practices have many opportunities to integrate its diverse components into their daily activities. Our findings suggest that from the patient perspective, most of the practices participating in the MAPCP Demonstration were delivering care in a way that was largely consistent with PCMH principles. Most participants described having accessible, well-coordinated, and highquality care and appropriate engagement in shared decisionmaking. These findings are similar to earlier, smaller qualitative studies of patient perspectives on PCMH care. ${ }^{8,9}$

Our findings also highlight several areas that may require enhanced transformation from the patient perspective. Relatively few participants used patient portals, indicating that practices' investments in new technologies may have limited effect when patients are not aware of their existence, cannot access them, or do not want to use them. Despite practices' efforts to expand access to care, participants still struggled to reach their PCPs and receive care when facing emergencies during nights and weekends, suggesting the need for additional effort in this area. Participants rarely received written plans or set specific goals with their physicians, which are critical tools for supporting patients' self-management of chronic conditions. Participants noted that although care was generally well-coordinated within a health care system, practices still need to improve coordination of care across systems, including the transfer EHR information and allowing for their PCPs to be engaged in their care when they were in the hospital. As primary care practices function within the realities of limited financial and staffing resources, adoption of PCMH components may require strategic prioritization. The need for prioritization is likely to escalate in the aftermath of COVID19 pandemic, as many primary care practices may struggle to maintain PCMH functions that they have put in place and introduce new ones.

Patients' perspectives also revealed persistent disparities and the need to enhance the paradigm of patient-centered care. Some participants from Medicaid and dually eligible groups reported feeling stigmatized or that their health concerns were not taken seriously, and some experienced challenges with coordination of care because many specialists would not accept their insurance. These findings are consistent with previous research, which has shown that people who are uninsured or who have Medicaid insurance often feel that they are treated poorly by their health care providers ${ }^{10,11}$ and that many providers are unwilling to accept patients with Medicaid coverage. ${ }^{12-14}$ These challenges suggest the need for enhanced focus on provider training in cultural competencies, reevaluation of effectiveness of cultural competency trainings across existing programs, and incentives to serve Medicaid beneficiaries and dually eligible.

As reported in other recent qualitative studies describing patient experiences with PCMHs, ${ }^{9}$ we also found that most participants did not know what a medical home was and were not aware that their practices were participating in an initiative seeking to enhance patient centeredness of care. In addition, few participants said that their practices had taken any steps to solicit their feedback. While practice improvement is a responsibility of practice staff, meaningful transformation cannot be achieved in the absence of patient engagement and buy-in. More recent iterations of CMS valued based care initiatives such as Accountable Care Organizations and the Comprehensive Primary Care Plus initiative require more structured patient engagement in organizational operations than those required in MAPCP, such as patient representation on organizational boards and advisory councils ${ }^{15}$ which may help to improve practices' responsiveness to patient needs and concerns. While seeking patient input and feedback is an important and necessary step forward, it is the willingness of practices and providers to act on patient input and recommendations that will facilitate change.

This study is subject to several limitations. First, the selection criteria for the study (that participants be Medicaid, Medicare, or dually eligible beneficiaries or caregivers of beneficiaries in eight select states and speak English fluently) led to a sample that was primarily non-Hispanic White, over age 60, and English-speaking; results may not be generalizable to other demographic groups. We were also unable to summarize the experiences of children enrolled in Medicaid because we were unable to recruit a sufficient number of caregivers of Medicaid children. However, because participants were drawn from eight different states, including both urban and rural areas, the study represents a much greater breadth of experiences than previous studies, and the high number of Medicaid and dually eligible beneficiaries ensures that perspectives of low-income and disabled populations are reflected. Second, 
because we collected data only from patients of practices that were participating in the MAPCP Demonstration, we cannot assess the extent to which their experiences may differ from those whose practices were not participating in the MAPCP Demonstration. Third, because the focus groups were conducted at one point in time, approximately 2.5 years after the MAPCP Demonstration began, we can only indirectly assess the extent to which patient experiences changed after their practices began their PCMH transformation. Finally, because each focus group included participants from more than one practice, it was not possible to link the comments from participants in specific focus groups to individual practices. As a result, we were unable to assess which practices had been most successful in achieving PCMH transformation or to what extent patient perceptions of care aligned with practice transformation efforts.

Additional research is needed to further understand PCMH transformation from the patient perspective. Research that links patient experiences to specific practices, including characteristics of the practices (e.g., practice culture, leadership, and physician engagement) and the PCMH transformation strategies the practices have implemented, could help elucidate how practice characteristics or strategies influence patient experiences.

Acknowledgments: The authors wish to acknowledge all those who helped in recruitment, data collection, and data analysis for the focus groups. They include the following:

RTI International:

Barbara Dalberth, Shellery Ebron, Megan Howard, Stephanie Kissam, Ann Larsen, Michael Little, Nancy McCall, Emily McClure, Lindsay Morris, Rebecca Perry

The Urban Institute:

Rachel Burton, Nicole Cafarella Lallemand, Kelly Devers, Emily Hayes

The Henne Group:

Jeff Henne, Sergio Garcia, Nyree Young

Corresponding Author: Ellen K. Wilson, PhD; RTI International, Research Triangle Park, NC, USA (e-mail: ellenwilson29@gmail.com).

Funding The analyses for this manuscript were performed under CMS contract number HHSM-500-2010-00021I. The contents of this paper are solely the responsibility of the authors and do not necessarily represent the official views of the US Department of Health and Human Services or any of its agencies.

\section{Compliance with Ethical Standards:}

All participants read and signed an informed consent form.
Conflict of Interest: The authors declare that they do not have a conflict of interest.

\section{REFERENCES}

1. Agency for Healthcare Research and Quality (AHRQ). Transforming the organization and delivery of primary care. U.S. Department of Health and Human Services, Patient Centered Medical Home Resource Center. n.d. https://pcmh.ahrq.gov. Accessed November 20, 2019.

2. Patient-Centered Primary Care Collaborative. Defining the medical home: A patient-centered philosophy that drives primary care excellence. 2019. https://www.pcpcc.org/about/medical-home. Accessed November 20, 2019.

3. Hall AG, Webb FJ, Scuderi CB, Tamayo-Friedel C, Harman JS. Differences in patient ratings of medical home domains among adults with diabetes: Comparisons across primary care sites. J Prim Care Community Health 2014;5(4):247-52.

4. Harder VS, Krulewitz J, Jones C, Wasserman RC, Shaw JS. Effects of patient-centered medical home transformation on child patient experience. J Am Board Fam Med 2016;29(1):60-8. https://doi.org/10.3122/ jabfm.2016.01.150066

5. Heyworth L, Bitton A, Lipsitz SR, et al. Patient-centered medical home transformation with payment reform: Patient experience outcomes. Am J Manag Care 2014;20(1):26-33.

6. Kern LM, Dhopeshwarkar RV, Edwards A, Kaushal R. Patient experience over time in patient-centered medical homes. Am J Manag Care 2013;19(5):403-10.

7. Sarinopoulos I, Bechel-Marriott DL, Malouin JM, Zhai S, Forney JC, Tanner CL. Patient experience with the patient-centered medical home in Michigan's statewide multi-payer demonstration: A cross-sectional study. J Gen Intern Med 2017;32(11):1202-9. https://doi.org/10.1007/ s11606-017-4139-2

8. Aysola J. Asking the patient about patient-centered medical homes: A qualitative analysis. J Gen Intern Med 2015;30(10):1461-7.

9. Tuepker A, Newell $\mathbf{S}$, Nicolaidis $\mathbf{C}$, et al. Veteran patient perspectives and experiences during implementation of a patient-centered medical home model. J Patient Exp 2018;5(2):107-13. https://doi.org/10.1177/ 2374373517731602

10. Allen H, Wright BJ, Harding $\mathbf{K}$, Broffman $\mathbf{L}$. The role of stigma in access to health care for the poor. Milbank $\mathrm{Q}$ 2014;92(2):289-318. https://doi. org/10.1111/1468-0009.12059

11. Han X, Call KT, Pintor JK, Alarcon-Espinoza G, Simon AB. Reports of insurance-based discrimination in health care and its association with access to care. Am J Public Health 2015;105 Suppl 3:S517-25. https:// doi.org/10.2105/AJPH.2015.302668

12. Cunningham PJ, Hadley $\mathbf{J}$. Effects of changes in incomes and practice circumstances on physicians' decisions to treat charity and Medicaid patients. Milbank Q 2008;86(1):91-123.

13. Decker SL. In 2011, nearly one-third of physicians said they would not accept new medicaid patients, but rising fees may help. Health Aff 2012;31(8): 1673-9.

14. Decker SL. No association found between The Medicaid Primary Care fee bump and physician-reported participation in Medicaid. Health Aff (Millwood) 2018;37(7):1092-8. https://doi.org/10.1377/hlthaff.2018. 0078

15. Plus CPC. CPC+ care delivery requirements crosswalk. Centers for Medicare and Medicaid Services. 2019. https://innovation.cms.gov/ Files/x/cpcplus-practicecaredlvreqs.pdf. Accessed November 20, 2019.

Publisher's Note: Springer Nature remains neutral with regard to jurisdictional claims in published maps and institutional affiliations. 